\title{
http://dx.doi.org/10.35381/racji.v5i8.591
}

\section{Análisis del derecho a la información pública en el Ecuador}

\section{Analysis of the right to public information in Ecuador}

\author{
Mayra Johana Bravo-Coronel \\ mbravo@ucacue.edu.ec \\ Universidad Católica De Cuenca, Cuenca \\ Ecuador \\ https://orcid.org/0000-0003-1436-3518 \\ Juan Carlos Erazo-Álvarez \\ jcerazo@ucacue.edu.ec \\ Universidad Católica de Cuenca, Cuenca \\ Ecuador \\ https://orcid.org/0000-0001-6480-2270 \\ Camilo Emanuel Pinos-Jaén \\ cpinosj@ucacue.edu.ec \\ Universidad Católica de Cuenca, Cuenca \\ Ecuador \\ https://orcid.org/0000-0002-0934-8471 \\ Cecilia Ivonne Narváez-Zurita \\ inarvaez@ucacue.edu.ec \\ Universidad Católica de Cuenca, Cuenca \\ Ecuador \\ https://orcid.org/0000-0002-7437-9880
}

Recibido: 14 de noviembre de 2019

Aprobado: 17 de diciembre de 2019

\section{RESUMEN}

En este artículo de revisión se exponen diferentes núcleos que permite un estudio referente a la doctrina y jurisprudencia para aplicabilidad del derecho al acceso a la información pública dentro de las instituciones públicas y privadas, por cuanto, la Legislación Nacional como la internacional manifiestan, que existen documentos considerados de carácter reservado y cierta restricción que se presenta al acceso de la 
información, y la LOTAIP determina dos vías para la obtención del acceso en la información, este Derecho Constitucional deber ser considera un deber social, garantizando de esta forma transparencia en la gestión y democracia. Se concluye que la Ley Orgánica de Transparencia y Acceso a la información pública a más de que se encuentra vigente por más 15 años se ha evidenciado que haya cumplido a cabalidad con su objetivo y no ha logrado mecanismos que sean de fácil y rápido acceso.

Descriptores: Derecho; Información; Pública; Seguridad jurídica; Principios del acceso a la información.

\begin{abstract}
In this review article different nuclei are exposed that allows a study referring to the doctrine and jurisprudence for applicability of the right to access to public information within public and private institutions, because, the National Legislation as the international state, that exist documents considered of a reserved nature and certain restriction that is presented to the access of the information, and the LOTAIP determines two ways to obtain the access in the information, this Constitutional Right must be considered a social duty, guaranteeing in this way transparency in the management and democracy. It is concluded that the Organic Law of Transparency and Access to public information, in addition to being in force for more than 15 years, has shown that it has fully complied with its objective and has not achieved mechanisms that are easily and quickly accessible.
\end{abstract}

Descriptors: Law; Information; Public; Legal security; Principles of access to information.

\title{
INTRODUCCIÓN
}

La Asamblea Constituyente de plenos poderes, convoca a una consulta popular, se aprueba mediante referéndum y entra en vigencia, en octubre del 2008 la Constitución del República del Ecuador del 2008 (CRE), en donde se consolida la apertura de un nuevo ciclo histórico para el Ecuador, y que sirvió como base para generar cambios en la sociedad, por ende con ciertas características y se incorpora nuevos derechos y se crea nuevos poderes del Estado (Cepeda, 2008). 
De manera tal que el ordenamiento jurídico consagra que, el Ecuador es un estado Constitucional de Derechos y Justicia, garantizando de esta forma el desarrollo humano, sus derechos, fortaleciendo a los diferentes organismos públicos y privados que pertenecen al estado con la finalidad de lograr un estado y una sociedad bien estructurada dentro del marco jurídico garantista en donde se vea plasmado en su totalidad el derecho a la ciudadanía, en donde ha servido a que los diferentes organismos públicos generen ciertas políticas para tratar de cumplir con las exigencias presentadas por la sociedad ecuatoriana (Ordoñez, 2010).

Dentro de la Constitución de la República del Ecuador del 2008 en la Sección Cuarta dentro del cual indica que en cuanto se refiere a Derecho al Acceso a la Información Pública en el art. 91. "La acción de acceso a la información pública tendrá por objeto garantizar el acceso a ella cuando ha sido denegada expresa o tácitamente, o cuando la que se ha proporcionado no sea completa o fidedigna. Podrá ser interpuesta incluso si la negativa se sustenta en el carácter secreto, reservado, confidencial o cualquiera otra clasificación de la información. El carácter reservado de la información deberá ser declarado con anterioridad a la petición, por autoridad competente y de acuerdo con la ley." (Asamblea Nacional Constituyente, 2008,art. 91).

Es por ello que según la pirámide del Kelsen, la Constitución prevalece ante cualquier otra Ley y por ende los derechos reconocidos en la Constitución de la Republica son de aplicación inmediata, directa y de estricto cumplimiento por todos los ecuatorianos, pues bien, los diferentes organismos del estado se han visto en la obligación de tratar de garantizar el derecho al acceso de la información pública, de tal forma fue concebida y promulgada el 18 de mayo de 2004, publicada en el Registro Oficial Nro. 337 La Ley Orgánica de Transparencia y Acceso a la Información Pública (LOTAIP), desde aquella fecha la información pública es reproducida y se encuentra a buen recaudo por todas los organismos del estado, pero no se ha cumplido como dispone el mandato legal por lo que no ha existido un mecanismo de fácil acceso a la información por cuanto esto 
debe ser canalizado de una mejor manera creando nuevas formas en donde la ciudadanía que desea obtener información sea de forma ágil y rápida.

En la actualidad lo puede obtener cumpliendo ciertos formalismos que más bien se ven involucrados recursos públicos de los cuales muchas veces el interesado se queda en el intento, siendo una posibilidad de agilizar, lo relacionado al infogobierno (Perozo Martín \& Chirinos Martínez, 2019).

Sin embargo, en la búsqueda de la verdad y justicia los ciudadanos proceden a solicitar a una Institución del Estado información, cumpliendo estándares constitucionales, legales, pero muchas veces no lo logran debido a que no existe la información o a su vez no es proporcionada por cuanto en la LOTAIP se regula la vía a la información pública, explica en una forma didáctica, pormenorizando, mas no un procedimiento práctico para obtener la información pública, ya que es muy importante que en esta ley se implemente una herramienta efectiva para el ejercicio, uso y goce de este derecho para el usuario (Vera, 2015).

Podríamos resumir a continuación problema de la presente investigación: ¿cómo crear mecanismos para el cumplimiento con el Derecho al Acceso a la Información Pública en la Ley Orgánica de Transparencia y Acceso a la Información Pública? Dentro de este orden de ideas el objetivo es Proponer una reforma que garanticen el cumplimiento de los derechos al acceso en la información pública en la LOTAIP.

\section{DESARROLLO}

Origen, principios rectores, límites, requisitos, información reservada y desarrollo del derecho al acceso de la información pública.

El origen donde nace el derecho al acceso a la información pública es en Suecia, en el año de 1766, fue el primer país en crear la ley de acceso a la información pública y para lo cual establecen unos mecanismos en donde los ciudadanos tenían acceso a los documentos que era reproducido por el gobierno, por consiguiente este derecho se encuentra amparado en legislación internacional; empezando por Declaración Universal 
de los Derechos Humano, documento que fue adoptado por la Asamblea General de las Naciones Unidas en el artículo 19, mediante el cual se reconoce que todo ser humano tiene derecho a la libertad de opinión y expresión y a través de este derecho parte a recibir informar, difundir por cualquier medo de expresión, a respetar las opiniones ajenas (Asamblea General de las Naciones Unidas, 1948).

El Pacto Internacional de los Derecho Civiles y Políticos, que entra en vigencia a partir del 23 de marzo de 1976, en donde todos los países que forman parte de este Pacto tienen el deber de promover el respeto universal y efectivo de los derechos humanos, y en su artículo 19 se dispone que toda persona que sea parte los países que conforman este Pacto tienen derecho a la libertada de expresión y que por el cual este derecho se deriva la libertad de buscar, recibir y difundir todo tipo de información a través del procedimiento que crea conveniente (Asamblea General de las Naciones Unidas, 1966). La Convención Americana sobre los derechos Humanos "Pacto de San José de Costa Rica" en donde los estados partes se comprometen a respetar a toda persona según su jurisdicción los derecho y libertades, origen social y/o condición social y en el artículo 13 , en este instrumento internación se garantiza el derecho que tiene todo ciudadano a la libertada de pensamiento y expresión, a recibir información y difundir información por el medio que sea a su elección (Convención Americana sobre Derechos Humanos, 1969).

Convención Europea para la Protección de los Derechos Humanos y de las Libertades Fundamentales publicado 4 del mes de noviembre de1950 en donde se debe respetar y velar por su complimiento en donde no se vulnere ningún derecho citado en la presente convención y en contenido en el artículo 10, manifiesta que toda persona tiene derecho a la libertada de expresión y por ende a recibir o comunicar ideas y por el cual tiene deberes, responsabilidades y siempre respetando el derecho que la ley determina como carácter reservado (Consejo de Europa, 1950).

En este instrumente internacional, Carta de los Derechos Fundamentales para la Unión Europea, promulga en 7 de diciembre de 2000, en su artículo 10 manifiesta la libertad 
que tiene todo ser unos de pensamiento, de conciencia y religión y que de igual forma la libertad expresión y libertada de recibir o comunicar ideas que puedan tener cierta injerencia de ciertas autoridades públicas, es seria sin consideración de fronteras (Parlamento Europeo, el Consejo de la Unión Europea y la Comisión Europea , 2000). Por ello, se evidencia que existe un derecho vinculado a lo manifestado por los instrumentos internacionales que va directamente ligado a derechos de libertad de expresión y acceso a recibir y difundir información en los medios que se consideren necesarios y en la CRE en dentro de su articulado número 91, garantiza una gestión transparente del Estado y en sus diferentes niveles de gobierno asegurado la legalidad en sus diferentes actos administrativos de tal manera que la ciudadanía crea en la transparencia de su gestión (Montenegro, 2016).

Y es así, donde nace la Ley Orgánica de Transparencia y Acceso a la Información Pública (LOTAIP) publicada en el año 2004, se encuentra basada en los convenios, pactos suscritos con el Ecuador, Constitución de la República del Ecuador, por el cual se crea principios de publicidad, y que el acceso a la información pública siendo este un mecanismos que busca garantizar espacios a la colectividad de participación en la ejecución de políticas públicas y que se va plasmando en los niveles de gobierno, estableciendo niveles de democracia para los ciudadanos, y los niveles de crecimiento en las policitas publicas mejora la gestión pública, por el cual crea un nivel de inclusión a todos los ciudadanos y así tienen una orientación y estar vigilantes al Estado debido a que el derecho presentado sea de forma transparente y que dentro del esta existan secreto o a su vez información privilegiada esto debe ser considerada como de carácter reservada (Asamblea Nacional del Ecuador, 2004).

En cuanto a lo que se refiere a los principios de los niveles de garantías a la información a lo que se refiere la CIDH, a la buena fe, a la mayor anunciación (Lanza, 2018). Con respecto a la Constitución de la República del Ecuador en el Titulo II, Capítulo I, artículo 11, manifiesta como principales los derechos a: identidad, seguida e contigua, inclusión, interés y pureza (Asamblea Nacional , 2008). A estas consideraciones lo debemos 
sumar a lo que manifiesta la Ley Orgánica de Transparencia y Acceso a la Información Pública por lo cual rigen dos principios; este parámetro se basa en cuanto al derecho de la ciudadanía en acceder a la información que sea generada por autoridad pública, las Instituciones del Estado ya sea Gobiernos Autónomos Descentralizados y Cuerpos Colegiados que administren fondos públicos y por cuanto deben generar mecanismos que estén al alcance la sociedad respecto al nivel de cumplimiento de sus actividades, ejecución de proyectos y del presupuesto.

El principio de máxima divulgación a buscar, recibir y difundir informes contenido en el artículo 13 de la Convención Americana. En este sentido, tanto la Corte Interamericana como la CIDH han establecido que el derecho de acceso a la información deber estar regido por el principio de divulgación, ... El acceso a la información pública es un derecho humano fundamental que establece, sujetos solo a un régimen limitado de excepciones. (Marino, 2012, p.4).

Por otra parte el principio de gratuidad, toda informacion que solicite cualquier ciudadano ante un organo del estado, es gratiuto cuando se utilice medios conveniconales fotocopias, envio en medios magneticos, correo electronico y en el caso que se genere algun costo por la reproduccion de la informacion estar a cargo del usuario y se debera cancelar previa la emision de la informacion por parte del usuario estos costos deben ser razonables y apegados a lo que determina la normativa, cuando sea por temas temas de busqueda y archivo por este trámite no se deberà cancelar alguna tasa o impuesto (Gómez, 2012).

Sin duda toda información que este en el poder del Estado deber es considerado como pública, únicamente la información de carácter reservada no es susceptible de entregársela y las restricciones deben ser consideradas para proteger información la seguridad nacional, esta información perdurará por un lapso de quince años desde su calificación, la clasificación no podrá realizar posterior a la solitud de la información.

La información reservada y confidencial, ... a) Estos instrumentos son motivados como reservados por el órgano rector, por motivos de salvaguardar la nación, ... 1) Los planes y ordenes de defensa nacional, militar, movilizaciones, de operaciones especiales y de bases e 
instalaciones militares ante posibles amenazas contra el Estado; 2) Información en el ámbito de la inteligencia, específicamente los planes, operaciones especiales y de bases e instalaciones militares ante posibles amenazas contra el estado; 3) La información sobre la ubicación del material bélico cuando este no entrañe peligro para la población; y, 4) Los fondos de uso reservado exclusiva, ente destinados para fines de la defensa nacional; $y$, b) Las informaciones expresamente establecidas como reservadas en las leyes vigentes (Congreso Nacional, 2004, art.17).

Por tal motivo, para obtener la investigación de documentos que se encuentren en poder de un organismos que pertenezca al estado, será mediante la vía administrativa previa la presentación de una solicitud que lo realice ya sea una persona Natural o Jurídica esta petición deberá contener datos del solicitante, dirección domiciliaria donde se deba notificar y la referencia exacta de lo solicitado, por el cual se atenderá en un tiempo de diez días y únicamente se podrá extender por 5 días adicionales por causas debidamente justificada que y que deberán ser comunicadas al solicitante el motivo de la prórroga, pues des ser el caso de que existiera una negativa en la entre de la información o a su vez no dar respuesta dentro del plazo señalado.

Esto dará lugar a la presentación de una Acción Constitucional y deberá ser presentado ante un juez en donde deberá ser presentada ante un juez que pertenezca al lugar donde tenga el domicilio la persona representante de la institución quien negó la información, y en este caso el juez o tribunal deberá conocer y convocar a audiencia única y en 24 resolver si es procedente o no y la persona que no esté de acuerdo con el fallo tiene tres días para apelar la decisión emitida por el Juez (Asamblea Nacional del Ecuador, 2009).

No procede con la entrega de la documentación cuando es considerada como carácter reservada o confidencial de conformidad a lo que contempla la LOTAIP en su artículo 17, esto deber se cumpliendo parámetro que, de forma fundamentada en las Disposiciones determinadas en la Convención Americana de Derechos Humanos, la CRE en su Art. 81, ni en este caso que no sea proporcionada o negada sin ningún fundamento o causas de que es considera de carácter reservado, el peticionario podrá 
interponer una acción Constricción que es la Acción de Acceso a la Información Pública, de igual forma como norma supletoria la persona que use o suministre información de carácter reservado será sancionado de conformidad según dispone, COIP.

\section{Derecho comparado, casos, índices de cumplimiento del derecho al acceso a la información pública.}

Se indica respecto al derecho comparado, por el cual se presente el cuadro 1, en donde se establece de forma sucinta en donde varios países puntualizan el derecho al acceso a la información pública.

\section{Cuadro 1}

Análisis de la normativa internacional

País Normativa

Chile

España

Brasil

Costa Rica
Con fecha 20 de abril de 2009, se crea la Ley ํo20.285

y es conocida Ley de Acceso a la Información Pública o Ley de Transparencia.

La Constitución Española en su artículo 105, dispone la regulación de la Ley de acceso de los ciudadanos excepto los que afecte a la seguridad del estado y defensa del estado.

La Constitución de Brasil, determina que todo órgano público está obligado en proporcionar documentos en general, salvo la documentación que es reservada para este País.

La Constitución de Costa Rica, garantiza el derecho al acceso a la información a los departamentos administrativos, salvo los que sean considerados 


\section{Colombia}

México secretos de Estado.

La Constitución Política de la Republica de Colombia, consagra que la ciudadanía tienen derecho acceder a la documentación salvo los determinados de carácter reservado y sea considerada secreto profesional, para esta legislación.

Promueve y garantiza todo el derecho que tiene una persona para acceder a la información pública que se encuentre en posición de los poderes de la unión, los órganos constitucionales y cualquier entidad federal.

Fuente: Elaboración propia. Resultado obtenido de la recolección de datos seleccionados de las Diferentes Constituciones, mediante la utilización de las expresiones: "accesos a la información pública", "Acción de Derecho al Acceso de la información pública".

En la trascendencia del tiempo ha sido incorporado el Derecho al Acceso de la Información de varios países y así también a lo que se refiere a nuestro país ya se encontraba contemplado en la Constitución del 1998 y en el año 2004 de promulga la Ley Orgánica de Transparencia y Acceso a la Información pública y en el año 2008 cuando entra en vigencia la nueva Constitucional de la República del Ecuador, en el artículo 18 numeral; "1. Buscar, recibir, intercambiar, producir y difundir información veraz, verificada, oportuna, contextualizada, plural, sin censura previa acerca de los hechos, acontecimientos y procesos de interés general, y con responsabilidad ulterior. 2. Acceder libremente a la información generada en entidades públicas, o en las privadas que manejen fondos del Estado o realicen funciones públicas. No existirá reserva de información excepto en los casos expresamente establecidos en la ley. En caso de violación a los derechos humanos, ninguna entidad pública negará la información" (Asamblea Nacional , 2008). 


\section{Cuadro 2}

Análisis cualitativo del derecho a la información pública

\section{Acción Sentencias}

\section{Constitucional}

Sentencias Acción de 013-16-SEP-CC; 167-18-SEP-CC; 003- 11-SEP-CC; 048-14-

Acceso a la SEP-CC; 256-17-SEP-CC; 14307-2019-00199; 107-17-SEP-

Información pública. CC.

Fuente: elaboración propia. Resultado obtenido de la recolección de datos seleccionados del portal digital de la Corte Constitucional del Ecuador, mediante la utilización de las expresiones: "accesos a la información pública", "Acción de Derecho al Acceso de la información pública".

Sin embargo, de la revisión digital de Corte Constitucional se puede evidenciar que existen caso presentado mediante la vía judicial en donde varios órganos del estado han negado el acceso a la información pública, vulnerando el derecho que consagra la Constitución de la República del Ecuador.

\section{Reforma a la Ley Orgánica de Transparencia y Acceso a la Información Pública en el Ecuador}

El en el Ecuador, pese a los intentos interpuesto por el Estado, en garantizar el Derecho a la Información Publica en donde se crea la LOTAIP, y la cual está vigente por más de 15 años y no se ha visto un resultado que vaya a satisfacer las necesidades de la ciudadanía al cien por ciento, registrando la falta de compromiso con esta normativa, tampoco se ha visto que la Defensoría del Pueblo haya implementado algún mecanismo en donde corrija mecanismos para un mejor acceso a la información, en otras palabras, el Defensor del Pueblo está en la obligación de solicitar las Instituciones que realicen los correctivos y como resultado la falta de la actualización a la LOTAIP.

Se evidencia que los órganos que está regulado por esta ley, no cumplen con lo que dispone en vista que para lo cual conforme lo determina el Informe anual sobre el 
cumplimiento del derecho de acceso a la información pública, periodo de enero a diciembre de 2018, presentado por la Defensoría del Pueblo en donde indica que en año 2018 registran en la base de datos respecto a las entidades públicas fueron 1505, 1085 Gobiernos Autónomos Descentralizados y 268 otras instituciones que manejan recurso públicos, y dentro de los cuales reportaron hasta el 29 de marzo del 2019 solo 1198 informes completos, 100 entidades presentaron sus informes de forma incompleta, en lo que respeta a las solicitudes que fueron presentadas antes los diferentes organismos en el año 2017 fue 100.910 y lo cual en el año 2018 fue de 140.646. En cuanto al término promedio para responder las solicitudes de acceso a la información pública en el año 2018 fue de un 6.08\%, dando como resultado que 707 solicitudes no se dieron respuesta (Defensoria del Pueblo del Ecuador, 2019).

Sin lugar, la LOTAIP, al momento de su elaboración, se dejó de lado puntos importantes que realizaría la correcta aplicación, esto es sumando que esta ley fue crea mucho antes que entre en vigencia la actual Constitución esto da lugar que se haga un cambio a lo que dispone la Constitución, por los acontecimientos requerimientos nacionales.

De esta forma se debería dar cumplimiento a esta ley, así como de la realización al Acceso a la Información Pública, es urgente que el país requiere una nueva ley acorde las exigencias y necesidad social, esto es mediante una proposición de reforma al capítulo que permita principalmente en la discrecionalidad de la información solicitada, que se unifique el procedimiento interno en todas los organismos del Estatales y Privados, debido a que este derecho esta vinculados a otros derechos como es la de participación y control social, es de gran importancia una reforma ya que con esta ley vigente se atribuye una ausencia y falta de reajuste de la norma, vacíos legales, falta de armonización con la carta magna y que esta reforma plasmara las expectativas del primer mandante que es el pueblo (Catoira, 2018).

Indudablemente para que se garantice el principio de legalidad y el principio de legitimidad se debe crear mecanismos que activen el acceso a la información pública, por lo tanto en nuestra en nuestro País es urgente que el estado rompa los esquemas 
privilegiados ya que de esta forma se garantizaría una verdadera participación ciudadana y la entrega de la información se de forma rápida y de fácil acceso.

Como resultado de manifestado y de acuerdo al informe presentado por la Institución encarga de vigilar que se dé estricto cumplimiento por parte de la entidad pública se demuestra que existe una falencia e incumplimiento en cuanto a otorgar la información a los ciudadanos que requieren de ella, por lo que, teniendo carácter de derecho fundamenta se muestra de forma clara que la Ley Orgánica de Transparencia y Acceso a la Información Publica en los siguientes artículos;

Artículo 9 inciso segundo, su responsabilidad será recibir y contestar las solitudes de acceso a la información, en el plazo perentorio de diez días, así mismo que pueda prorrogarse por cinco días más, por causas debidamente justificadas e informadas al peticionario. Artículo 19.- De la solicitud y sus requisitos.- El interesado a acceder a la información pública que reposa, manejan o producen las personas jurídicas de derecho público y demás entes señalados en el artículo 1 de la presente Ley, deberán hacerlos mediante solicitud escrita ante el titular de la institución. En dicha solicitud deberá constan el fona clara la identificación del solicitante y la ubicación de los datos o temas motivo de la solicitud, la cual será contestada en el plazo señalado en el artículo 9 de esta Ley. (Asamblea Nacional del Ecuador, 2004) (Congreso Nacional, 2004)

En razón de la problemática expuesta la reforma que se plantea es;

Artículo 9 inciso segundo; La responsabilidad será recibir y contestar las solitudes de acceso a la información, en el plazo de siete días, y con una prorrogarse por tres días más, por causas debidamente justificadas e informadas al peticionario. Artículo 19.- De la solicitud y sus requisitos.- El interesado a acceder a la información pública que reposa, manejan o producen las personas jurídicas de derecho público y demás entes señalados en el artículo 1 de la presente Ley, deberán hacerlo mediante solicitud escrita ante el titular de la institución y de igual forma a través de la página web institucional únicamente llenando el formulario de solicitud de información o a su vez a través de correo electrónico.

En dicha solicitud deberá constan la fona clara la identificación del solicitante y la ubicación de los datos o temas motivo de la solicitud, la cual será contestada en el 
plazo señalado en el artículo 9 de esta Ley. A continuación, se presenta el deber ser de la investigación:

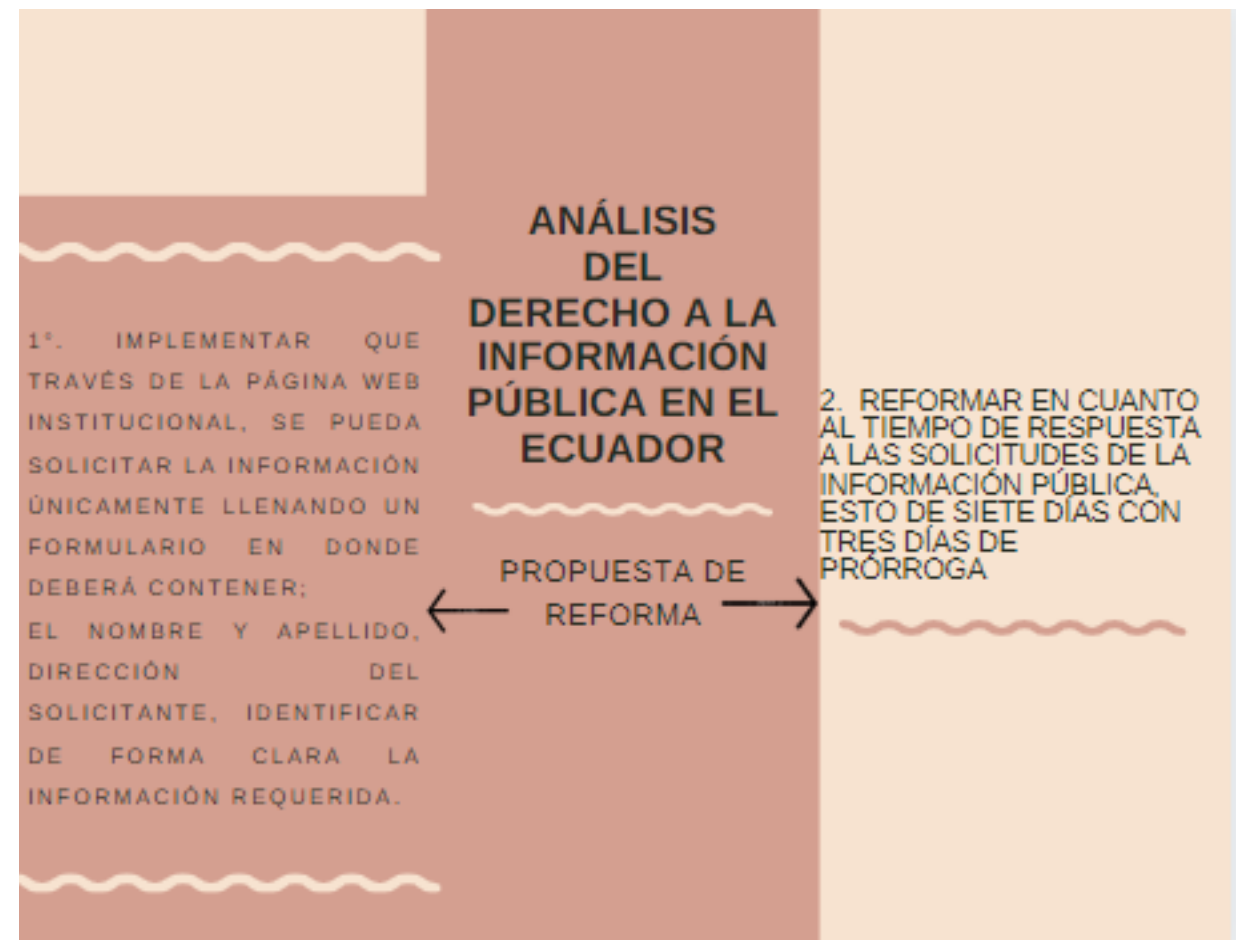

Figura 1 Análisis del derecho a la información pública

\section{METODOLOGÍA}

La metodología que fue empleada en la investigación, se basó según el enfoque cualitativo utilizando la recolección y análisis de una tipología documental, en donde consistió en la recopilación y recolección de información por medio de lectura y critica de documentos, fundada desde la perspectiva descriptiva en función a la determinación de las causas del problema (Narváez, Monagas y Erazo, 2019). Los métodos aplicados son Inductivo-Deductivo, son estrategias de razonamiento lógico, siendo que el inductivo fue utilizado para llegar a la conclusión, ambos métodos son importantes en la reproducción de conocimiento históricos (Peneque, 1998). 
Durante la investigación como el razonamiento lógico que, partiendo de los casos particulares, se elevan a conocimientos generales, históricos - lógico, que está vinculada a establecer un vínculo entre conocimientos históricos lo actual, fue necesario empezar con premisas verdades para llegar a conclusiones validad (Dávila, 2006).

\section{APORTES GENERADOS}

Sobre lo expuesto en el presente trabajo de investigación se realiza el siguiente análisis; la Ley Orgánica de Transparencia y Acceso a la Información Pública entro en vigencia a partir de mayo de 2004, no se ha visto que haya cumplido el rol que la sociedad necesita, en donde se inobserva a la LOTAIP, en donde no existe una normativa y vacíos legales que vaya de conformidad a lo que dispone la Constitución de la República del Ecuador y que esté acorde a la nación y en donde se vea plasmado un buen manejo de la administración publica en sus diferentes niveles, democrático y eficaz, por se debe crear mecanismos de forma rápida donde se generar espacios a la colectividad de participación en la ejecución de los las políticas pública y que este se vea plasmado dentro de los niveles de gobierno.

Se establecen así niveles de democracia para los ciudadanos, por cuanto todos tenemos el derecho e interés de conocer el trabajo que realizan las diferentes instituciones públicas y privadas que forman parte del Estado ecuatoriano, debido que no es posible que dentro de un estado existan secretos o a su vez información privilegiada o con algún interés de hacer daño a una tercera persona, desnaturalizando el derecho al acceso de la información pública.

Bajo este argumento, es importante indicar que es un derecho fundamental consagrado en la carta magna, se debe fortalecer a los diferentes órganos del estado o a su vez se debe corregir lo que falto, así contar con un mecanismo de autocorrección o aprendizaje y que sea satisfactorio para la colectividad.

Básicamente en entiende que la información pública que sea generada por autoridad pública, las Instituciones del Estado estos sean Gobiernos Autónomos Descentralizados 
y Cuerpos Colegiados que administren recursos públicos son dueños de la información que se haya reproducido y que la contestación presentada por un ciudadano deber ser rápida, eficiente y que la administración pública según lo Dispone el Código Orgánico Administrativo que todas la actuaciones deber dar cumplimiento inmediato, evitando retardos injustificados y que los requisitos sean básicos, por cuanto si revisamos que en la actualidad no se cumple y que muchas veces el usuario únicamente pierde su tiempo y dinero.

Se considera que la institución pública que está regulada por la Ley Orgánica de Transparencia y Acceso a la Información Pública, se encuentra en la obligación de difundirla en la página web institucional información que deber ser organizada, organizada por temas, de forma cronológica o secuencial con la finalidad de que esta sea de fácil acceso al público de conformidad a lo dispone el artículo 7 de la Ley Orgánica de Transparencia, pero si vemos que muchas Instituciones no tiene ni página web institucional por ejemplo un Gobiernos Autónomo Descentralizado parroquial y que muchas veces no existe internet por diferentes motivos ya sea por la distancia o porque este servicio aun no llega a la parroquia.

Ante las exigencias de la sociedad no solamente debe ser considerado como un derecho fundamental si no como un deber que tiene en Estado garantizando de esta manera democracia, transparencia priorizando la entrega de la información que se encuentre en diferentes medios digitales por cuanto de esta forma se garantizaría el principio de celeridad y gratuidad de la información y se ahorraría recursos públicos, debido a que hoy en día se realiza publicaciones en redes sociales.

Se convoca a reuniones masivas cuando al realizar estos eventos se comprometen recursos que bien estos debería ser utilizados en proyectos o creación de políticas públicas que vayan en beneficio de la colectividad, generando nuevos lineamientos que sirvan de ayuda a la sociedad no solo en la parte de la interpretación de la ley, sino de igual forma en donde se busque implementar medidas específicas para implementar el contenido de la norma esto es generando una herramienta de carácter práctico que 
provea la información completa y no en 10 días y con prorroga 15 días sino más bien que sea en 7 días incluso la prórroga.

Por otro lado el derecho al acceso a la información pública, genera otros derechos especialmente para quienes está en posición subordinada y están siendo vulnerados, si bien es cierto que a partir de dicha promulgación de la Ley Orgánica Transparencia y Acceso a la Información Pública se han producido cambios institucionales y normativos, por cuanto es necesario que esta Ley debe ser reformada así como de igual forma se debe exigir a los entes encargado de vigilar el cumplimiento y promotores de la vía de la información pública como son el Consejo de Participación Ciudadana y Control Social y la Defensoría del Pueblo garantice el cumplimiento y se elabore un paquete de reformas y que sean enviada a la Asamblea para que sea reformada la Ley Orgánica de Transparencia y Acceso a la Información Pública.

\section{REFERENCIAS CONSULTADAS}

1. Asamblea General de las Naciones Unidas . (10 de Diciembre de 1948). Declaración Universal de los Derechos Humanos.

2. Asamblea General de las Naciones Unidas. (23 de Marzo de 1966). Pacto Internacional de Derechos Civiles y Políticos. Asamblea General de las Naciones Unidas.

3. Asamblea Nacional . (2008). Constitución de la Republica del Ecuador. Constitución de la Republica del Ecuador. Montecristí, Manabí, Ecuador : Registro Oficial.

4. Asamblea Nacional del Ecuador. (18 de mayo de 2004). Ley Organica de Transparencia y Acceso a la Información Pública. Ley Organica de Transparencia y Acceso a la Información Pública.

5. Asamblea Nacional del Ecuador. (25 de Octubre de 2009). Ley Orgánica de Garantías Jurisdiccionales y Control Constitucional. Ley Orgánica de Garantías Jurisdiccionales y Control Constitucional. Quito, Pichincha, Ecuador: Registro Oficial Suplemento 52. 
6. Catoira, A. A. (2018). El derecho de acceso a la información pública como derecho fundamental en América Latina. La acción constitucional de acceso a la información pública en el Ecuador. Cuadernos Manuel Giménez Abad, 70-89.

7. Cepeda, J. J. (2008). Visión histórica de las constituciones de 1998 y 2008. Lirg.

8. Congreso Nacional. (18 de Mayo de 2004). Ley Orgánica de Transparencia y Acceso a la Información Pública. Ley Orgánica de Transparencia y Acceso a la Información Pública. Quito, Pichincha, Ecuador: Registro Oficial 337.

9. Consejo de Europa. (4 de Noviembre de 1950). Convenio Europeo para la Protección de los Derechos Humanos y de las Libertades Fundamentales. Convención Europea de Derechos Humanos.

10. Convención Americana sobre Derechos Humanos. (22 de Noviembre de 1969). Convención Americana sobre Derechos Humanos. Convención Americana sobre Derechos Humanos. San José, Costa Rica.

11. Dávila Newman, G. (2006). El razonamiento inductivo y deductivo dentro del procedieminto en ciencias experimentales sociales. Laurus, 180-205.

12. Defensoria del Pueblo del Ecuador. (2019). Informe anual sobre el cumpliento del derecho de acceso a la información pública periodo de enero a diciembre de 2018. Informe anual sobre el cumpliento del derecho de acceso a la información pública periodo de enero a diciembre de 201.

13. Gómez Gallardo, P. (2012). Sobre el ejercicio responsable de la libertad de expresión. Revista Mexicana de Comunicación, 42-43.

14. Hernández Godínez, A. (2010). El acceso a la información pública.

15. Lanza, E. (2018). Relatoria Especial para la libertad de expresión. Washington: Comisión Interamericana de Derechos Humanos.

16. Marino, C. B. (2012). El Derecho al Acceso a la Informacion Publica en el marco juridico Interamericano. Relatoría Especial para la Libertad de Expresión.

17. Montenegro, D. M. (2016). El Derecho de Acceso a la Información Pública y su vinculación con las Nuevas Tecnologías de la Información y Comunicación.

18. Narváez Zurita, I., Monagas Docasal, M., \& Erazo Álvarez, J. C. (2019). Las competencias laborales en el sector de textiles y confecciones en la provincia Tungurahua, Ecuador. Labor Competencies in the Textile and Garment Sector in the Province of Tungurahua, Ecuador. COFIN Habana, 35. 
19. Ordoñez Santa Cruz, P. B. (2010). La defensoria del pueblo según la constitucion. Diplomado superior en derecho constitucional y derechos.

20. Parlamento Europeo, el Consejo de la Unión Europea y la Comisión Europea . (7 de Diciembre de 2000). Carta de los Derechos Fundamentales de la Unión Europea. Carta de los Derechos Fundamentales de la Unión Europea. Estrasburgo.

21. Peneque, R. J. (1998). Metodologia de la Investigación. La Habana.

22. Perozo Martín, R., \& Chirinos Martínez, A. (2019). Incidencias de la Tecnología web 2.0 en el contexto de la gobernanza y la gobernabilidad. IUSTITIA SOCIALIS, 4(6), 90-116. doi:http://dx.doi.org/10.35381/racji.v4i6.291

23. Vera Puebla, M. (2015). Derecho al acceso a la información publica. Quito: Fundación Regional de Asesoría en Derechos Humanos INREDH. 